\title{
MULTI-GENE PROBING OF AFLATOXIGENIC MOLDS IN FOOD USING PCR AND IMMUNOLOGICAL TECHNIQUES
}

\author{
SHAPIRA, R. and N. PASTER ${ }^{1}$ \\ Institute of Biochemistry, Food Science and Nutrition, Faculty of Agriculture \\ The Hebrew University of Jerusalem, Rehovot 76100, Israel \\ ${ }^{1}$ Department of Stored Products Agricultural Research Organization, \\ The Volcani Center, Bet Dagan 50250, Israel
}

\begin{abstract}
Aflatoxins are carcinogenic metabolites produced by several members of the Aspergillus flavus group in grains and foods. Three genes: ver-1, omt-1 and apa-2, coding for key enzymes and a regulatory factor in aflatoxin biosynthesis respectively, have been identified and their DNA sequences published. In the present study, three primer pairs were generated, each complementing the coding portion of one of the genes. DNA extracted from mycelia of five Aspergillus species, four Penicillium species and two Fusarium species were used as PCR templates for each of the primer pairs. DNA extracted from peanut, corn and three insect species commonly found in stored grains was also tested. Positive results (DNA amplification) were achieved only with DNA of the aflatoxigenic molds $A$. parasiticus and $A$. flavus in all three primer pairs. The detection limit of the PCR was determined using the primer pairs complementing the omt-1 and ver-1 genes. Sterile corn flour was inoculated separately with six different molds, each at several spore concentrations. Positive results were only obtained following a 24-h incubation in enriched media, with extracts of corn inoculated with $A$. parasiticus or $A$. flavus, even at the lowest spore concentration applied $\left(10^{2}\right.$ spores/g). No DNA amplification was observed from corn inoculated with other molds, even at the highest inoculum level $\left(10^{6}\right.$ spores $\left./ g\right)$.
\end{abstract}

Polyclonal antibodies (pAb) were raised against an aflatoxigenic strain of $A$. parasiticus using two chimeric proteins, expressed in Escherichia coli as separate products, of the genes ver-1 and apa-2. The gene products were amplified by PCR and each was cloned into the $E$. coli expression vector pGEX2T. Upon induction, the bacteria overexpressed a $38 \mathrm{kDa}$ and $33 \mathrm{kDA}$ chimeric proteins corresponding to the $\mathrm{N}$-terminal domain of the genes ver- 1 and apa-2, respectively. The chimeric proteins were isolated and affinity-purified for use as antigens. The specificity of the raised antibodies was examined by ELISA. The polyclonal antibodies elicited against the chimeric proteins were highly specific, showing significantly higher ELISA absorbance values $\left(\mathrm{A}_{405}\right)$ against $A$. parasiticus and $A$. flavus, then against the other fungi tested and the corn grain. Such a "multi - antibody system" combined with the PCR technique, could provide a useful tool for the rapid, sensitive and accurate detection of aflatoxin producers present in grains and foods. 